Canadian

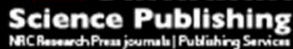

Canadian Geotechnical Journal Revue canadienne de géotechnique

\title{
Laboratory Characterization and Discrete Element Modeling of Shrinkage and Cracking in Clay Layer
}

\begin{tabular}{|r|l|}
\hline Journal: & Canadian Geotechnical Journal \\
\hline Manuscript ID & cgj-2016-0674.R1 \\
\hline Manuscript Type: & Article \\
\hline Date Submitted by the Author: & 03-May-2017 \\
\hline Complete List of Authors: & $\begin{array}{l}\text { Guo, Yuan; Case Western Reserve University, Civil Engineering } \\
\text { Han, Chanjuan; Case Western Reserve University, Civil Engineering } \\
\text { Yu, Xiong; Case Western Reserve University, Civil Engineering }\end{array}$ \\
\hline Keyword: & dissication crack, shrinkage, discrete element model, crack monitoring \\
\hline & \multicolumn{2}{l}{} \\
\hline
\end{tabular}

SCHOLARONE ${ }^{\text {IM }}$

Manuscripts 


\section{Laboratory Characterization and Discrete Element Modeling of Shrinkage and Cracking} in Clay Layer

$5{ }^{1}$ Graduate Assistant, Department of Civil Engineering, Case Western Reserve University, 2104 Adelbert

6 Road, Bingham 269, Cleveland, OH, E-mail: yxg223@case.edu.

$7 \quad{ }^{2}$ Graduate Assistant, Department of Civil Engineering, Case Western Reserve University, 2104 Adelbert 8 Road, Bingham 203D, Cleveland, OH, E-mail: cxh432@case.edu.

$93 *$ Professor, Corresponding Author, Department of Civil Engineering, Case Western Reserve University, 102104 Adelbert Road, Bingham 206, Cleveland, OH, Phone: 216-368-6247, E-mail: xiong.yu@case.edu, 11 corresponding author.

13 Abstract

15 The performance of a variety of geostructures such as compacted clay liners, earth dams, and 16 pavement embankments are compromised by soil cracking. Experiments are set up to monitor 17 the drying process of a clay layer under controlled temperature and humidity conditions. The 18 gravimetric water content and the images are captured automatically. The volumetric shrinkage 19 of the bentonite sample as well as the crack patterns are determined from images. The monitored 20 volumetric strain development is used to implement the Discrete Element Model (DEM) to 21 simulate the drying shrinkage and desiccation cracking. Model parameters are calibrated 22 through unconfined compression tests on clay specimens at different water content. This 23 simplified calibration procedure allows to characterize the soil behaviors in the mesoscale and 24 bypass the complex physiochemical processes involved. The initiation and propagation of cracks 
25 from the DEM model agree well with the phenomena observed in the laboratory experiments.

26 The influence of boundary constraint and sample thickness on the crack patterns are analyzed,

27 which include the use of hydrophobic coating to diminish the boundary constraint. Major

28 features of desiccation cracking can be replicated with the computational procedures. Boundary

29 constraint, including surface roughness and strength of boundary layer, is found to significantly

30 influence the final crack patterns.

32 Keywords: desiccation crack, drying shrinkage, bentonite, crack pattern, Discrete Element Method (DEM)

Introduction

Soil cracking is a critical issue in geotechnical engineering, as it may cause damage to embankments and earth dams (Dyer et al. 2007; Kakuturu and Reddi 2006), undermine the stability of slopes (Utili 2013), deteriorate the performance of stabilized pavements (Kodikara and Chakrabarti 2005), and induce the leakage of landfill liners and covers (Daniel and Wu 1993;

42 Albrecht and Benson 2001; Rayhani 2008; Peron et al. 2009a). Desiccation cracking, which occurs when soils are restrained while drying and undergoing volumetric shrinkage, is regarded 44 as a critical engineering problem especially for expansive soils. 
composition largely affect the formation of desiccation cracking (Yesiller 2000; El Maarry 2015). Addition of non-swelling silica fume to clayey soils could reduce the shrink-swell behaviors (Kalkan 2009). The initiation and propagation of cracks while drying are also determined by some environmental factors. Salt concentration, relative humidity and temperature, which may significantly change the water evaporation rate, could affect the formation of desiccation cracking (Gebrenegus 2011; Hedan et al. 2014; Shokri 2015). Cyclic freezing and thawing could change the shape of the desiccation polygons ( $\mathrm{Lu} \mathrm{2016).}$

Cracking water content, or the moisture content at which crack starts to occur, varies for the same soil under different testing conditions, e.g., sample thickness, bottom contact, and evaporation rate (Nahlawi and Kodikara 2006; Tang 2011a; Zielinski 2014). Under the same testing condition, the drying process of cohesive soil can be divided into two stages separated by the air entry point (Peron 2009a). Above the point, the soil is fully saturated and the evaporation rate remains constant. Below the point, the degree of saturation is smaller than $100 \%$ and the evaporation rate decreases due to the significant increase of suction. Laboratory monitoring on clayey soil showed that $90 \%$ of the cracks took place during the constant evaporation rate period before the air entry point (Tang 2011a).

Modeling of soil cracking while drying is still challenging due to the complex influencing factors, including clay minerology, double layer interaction, soil suction (Anderson and Lu 2001; Santamarina 2001), and the discontinuity involved when cracking. The mesh fragmentation method, which is a further implementation of the Finite Element Method (FEM), is promising in simulating the formation of desiccation cracks (Sánchez 2014). The migration of water during drying can also be solved through weak coupled diffusion equation embedded in the FEM model (Hirobe and Oguni 2016). Besides that, the Discrete Element Method (DEM) provides an 
71 alternative way to model the discontinuity of clayey soils while drying (El Youssoufi 2005;

72 Amarasiri 2011; Amarisiri 2014; Gui and Zhao 2015; Gui 2016). In the DEM model, discrete

73 polygonal-shaped blocks or spherical particles are used to simulate soils in the aggregate scale

$74(0.1 \mathrm{~mm} \sim 10.0 \mathrm{~mm})$. Some researchers also developed the particle scale model $(0.1 \mu m \sim 10.0$

$75 \mu m$ ) based on the DEM, which considers the mechanical interactions between clay particles

76 (Anderson and Lu 2001; Katti 2009). However large dimensional modeling of clayey soils

77 under the microscale is still challenging due to the limitation of current computational power.

Aside from considering the complicated clay particle interactions, a simplified intraaggregate structure model may be suitable to explain most of the cracking behaviors (Chertkov 2008; Bagherieh 2009). In this model, natural soil is regarded as a medium consisted of soil aggregates, and aggregates are separated by fine inter-aggregate pores. Volume of the soil aggregate changes with water content (Tang 2011b). Based on these assumptions, the mesoscale DEM model was built to describe the cracking process (El Youssoufi 2005; Peron 2009b; Sima 2014). The formation and propagation of cracks are simulated at the aggregate level through proper scaling of particle size and careful selection of contact parameters. Experiments show that the Young's modulus and undrained shear strength of clayey soils are highly related to soil water content (Borgesson 2001; Lu and Kaya 2013; Tisato and Marelli 2013; Byun 2013; Stirling 2015). These raise difficulties in the parameter calibration of the DEM model. understand the cracking behaviors of cohesive soils. This is relevant to the assessment and

91 improvement of the performance of a variety of geostructures such as the compacted clay liners

92 for solid waste landfill, earth dams, and moisture stability of pavement embankments. In this 93 study, the desiccation cracking of a thin bentonite layer is prepared in a petri dish and is 
94 monitored in the laboratory under controlled temperature and relative humidity conditions. A 95 DEM model is built to replicate the drying shrinkage of bentonite sample. The cracking 96 behaviors of bentonites with different sample thicknesses and bottom constraints are compared 97 and analyzed through laboratory experiment and numerical simulations. It is shown that the 98 desiccation cracking of bentonite layer is highly sensitive to the initial thickness and boundary 99 constraints (i.e., boundary roughness and boundary adhesion). The observations may offer 100 insight on the cracking behaviors of expansive soils and therefore could lead to improved 101 countermeasures to mitigate the cracking induced performance issues.

102

\section{Laboratory Experiment}

104

The drying process of a thin bentonite layer in a petri dish was monitored through a custom-built monitoring system under controlled temperature and humidity conditions. The measured properties of bentonite were used subsequently in the numerical model for the further analysis.

\section{Material and methods}

111 THERM-EX GROUT ${ }^{\mathrm{TM}}$ bentonite provided by the Wyo-Ben Inc. was used in the following 112 experiments. Product sheet from manufacturer indicates the specific gravity of bentonite is $1132.45 \sim 2.55$ at $20^{\circ} \mathrm{C}$, and the mean particle size is $7.0 \mu \mathrm{m}$ measured by the particle size analyzer. 114 The liquid limit and plastic limit are $239 \%$ and $52 \%$ respectively measured under room 115 temperature (ASTM D4318, 2000).

116 Figure 1 gives the experimental setup of the custom-built cracking monitoring system. 
117 THERM-EX GROUT ${ }^{\mathrm{TM}}$ bentonite without additional treatment was first mixed with deionized

118 water to the initial water content of $425 \%$. The slurry was then stirred for 30 minutes to form a

119 uniform mixture. The well-mixed slurry was poured into a petri dish $(8.0 \mathrm{~cm}$ in diameter $)$ and

120 then sealed and cured for 24 hours for fully saturation. This well-prepared sample was put in an

121 insulated chamber under controlled temperature $\left(23^{\circ} \mathrm{C} \pm 2^{\circ} \mathrm{C}\right)$ and relative humidity $(30 \% \pm 5 \%)$.

122 The gravimetric water content was tracked during the experiment through the scale reading. The

123 initiation and propagation of cracks during drying were recorded through a camera mounted on

124 the top. A laser displacement sensor was pointed to the center of the dish to keep measuring the

125 vertical shrinkage.

127 Laboratory results

129 The volumetric shrinkage of bentonite clay was monitored through the video camera. Assume

130 the sample shrinks uniformly and evenly, the volumetric strain can be obtained through the

131 image analysis together with the thickness reading from the laser displacement sensor pointing to

132 the center of the sample. However bentonite sample tends to crack and curl during drying due to

133 the existence of boundary constraint and the non-uniform moisture distribution. To minimize the

134 boundary constraint, a hydrophobic coating was sprayed on the petri dish surface. A thin

135 bentonite layer with a thickness of $0.75 \mathrm{~cm}$ was prepared to diminish the moisture difference

136 along the depth direction, and also between the center and the edge.

137 The monitoring result is shown in Figure 2. By applying the hydrophobic coating, the

138 boundary constraint was minimized and only one small crack formed finally. Curling of the

139 sample was delayed until the water content reached $22 \%$, while in the regular petri dish the 
140 curling water content was as large as $71 \%$. A comparison of the final desiccated samples in the 141 coated and uncoated dishes is given in Figure 3. It should be noted that before curling occurred, 142 sample in the coated dish dried uniformly and the thickness can be regarded as the same. The 143 shrinkage volume after curling $(w<22 \%)$ has been corrected according to the final soil density, 144 which was measured from three additional samples drying under the same condition.

145 The decrease of gravimetric water content of bentonite sample over time is shown in 146 Figure 4. The evaporation rate (proportional to the gradient of water content curve) remains 147 constant in the first stage but decreases as the water content drops to $150 \%$ due to the increase of 148 soil suction. Figure 5 provides the relationship between the volumetric strain and the gravimetric 149 water content. The volumetric strain is acquired through image analysis together with sample 150 thickness measurement. A quadratic regression between volumetric strain $\left(\varepsilon_{w}\right)$ and gravimetric 151 water content $(w)$ is given below.

$\varepsilon_{w}=-0.018 w^{2}-0.1336 w+0.8849$

153 Numerical Modeling of Desiccation Cracking of Bentonite

155 A Discrete Element Method (DEM) model was built to simulate the formation and propagation 156 of soil desiccation cracks. The crack pattern with different boundary conditions, including 157 sample thickness, surface roughness, and clay-dish interface strength, has been analyzed 158 numerically and experimentally. 
162 Temperature and relative humidity are important factors affecting soil cracking behaviors, as 163 they may significantly change the evaporation rate of soil samples (Rodríguez et al. 2007; Tang 164 2008; Tang et al. 2010). In this study, a simplified condition was assumed where a low 165 evaporation rate is maintained during the experiment and soil sample dries uniformly. From 166 laboratory experiments, the decreasing rate of soil water content is less than $0.1 \% / \mathrm{min}$ even in 167 the first few hours (Figure 4). In the DEM model, the volumetric shrinkage of bentonite was 168 simulated through proper scaling of particle size. For spherical particles, the scaled radius can be 169 calculated based on the volumetric strain of clay sample through Eq. (2). The quadratic 170 regression between volumetric strain and water content (Eq. (1)) was used to calculate the 171 scaling coefficient $\alpha_{w}$ at different water content.

$1-\varepsilon_{w}=1-\frac{\Delta V}{V}=\frac{\left(R_{w}\right)^{3}}{R_{0}^{3}}=\alpha_{w}{ }^{3}$

172 where $\varepsilon_{w}$ is the volumetric strain at a water content of $w ; V$ is the volume of the clay aggregate;

$173 R_{w}$ is the particle radius at the water content of $w ; R_{0}$ is the initial particle radius; $\alpha_{w}$ is the 174 scaling coefficient at the water content of $w$, and $R_{w}=\alpha_{w} R_{0}$.

175 The contact model between two particles is given in Figure 6. The Kelvin-Voigt model is 176 used for both the normal and tangential directions. A frictional slider is included in the tangential 177 direction to simulate sliding. The particle parameters characterize this contact model include: the 178 normal and tangential spring stiffness $(K n$ and $K s)$, particle frictional coefficient $(f)$, the normal 179 and tangential bond strength $\left(\sigma_{n}\right.$ and $\left.\sigma_{s}\right)$, and viscous damping ratio $(c)$. Besides the viscous 180 damping, the PFC3D also provides the local damping, which is directly applied in the 181 momentum equation to achieve static gravitational balance. In this paper, the viscous damping 182 ratio is set to 0.0 for simplicity and the local damping is set to the default value of 0.7 for 183 computational efficiency. 


\section{Calibration of particle parameters}

187 A series of Unconfined Compression Tests (UCTs) were conducted for the purpose of parameter 188 calibration (ASTM D2166 2013). Bentonite samples with seven different water content levels 189 were prepared and sealed for 48 hours for moisture homogenization, and then tested accordingly. 190 A scaled DEM sample was built to calibrate the particle parameters through inverse analysis. 191 This simplified calibration method bypasses the complicated consideration of soil suction and 192 clay mineral interaction, and is able to characterize the macroscale mechanical behaviors of 193 bentonite at different water content. Figure 7 compares the UCT sample with the DEM model. 194 The DEM model has been scaled down to a diameter of $10.0 \mathrm{~mm}$ and a height of $20.0 \mathrm{~mm}$ to 195 improve computational efficiency. Particles in the DEM model have the same diameter of 1.0 $196 \mathrm{~mm}$. The loading velocity has been scaled according to the scale factor. The frictional 197 coefficient between particles was calibrated through the failure plane angle. It is shown 198 experimentally that the angle of shear plane changes little at different moisture content. In the

199 numerical model, angle of shear plane is mainly determined by the frictional coefficient $f$. A 200 frictional coefficient of 0.40 gives the most analogous result compared with the experiment 201 (Figure 7).

The Young's modulus and unconfined compressive strength were used to calibrate 203 particle spring stiffness and bond strength. Previous research shows the ratio of normal and 204 tangential contact stiffness influences the Poisson's ratio of materials (Wang and Mora 2008; Liu 205 et al. 2013). Here for this paper, the desiccation cracking of a thin clay layer can be regarded as 206 a one-dimensional process, so that both spring stiffness and bond strength were simplified to be 
207 the same in the normal and tangential directions $\left(K n=K s\right.$ and $\left.\sigma_{n}=\sigma_{s}\right)$. The simulation results

208 provided in the following context show this simplified method provides accurate calibrations of

209 clay samples in terms of soil cracking simulation. Two piecewise functions have been used in

210 the regression of stiffness and bond strength with subdomains separated by soil plastic limit $(w=$

$21150 \%$ ), as is shown in Figure 8a/b. A linear expression is used for the low-moisture subdomain

212 and an exponential expression is used for the high-moisture subdomain, as is given in Eqs. (3-4).

$$
\begin{aligned}
K_{n / s} & = \begin{cases}3.7210 \times 10^{6}-7.2151 \times 10^{6} w, & w<50 \% \\
18962 w^{-2.581}, & w \geq 50 \%\end{cases} \\
\sigma_{n / s} & = \begin{cases}5.7047-10.3430 w, & w<50 \% \\
0.0918 w^{-2.538}, & w \geq 50 \%\end{cases}
\end{aligned}
$$

213 where $K_{n / s}$ is the normal/tangential spring stiffness $(\mathrm{N} / \mathrm{m}) ; w$ is the gravimetric water content, 214 and $w=M_{\text {water }} / M_{\text {soil }} ; \sigma_{n / s}$ is the normal/tangential adhesive strength $(\mathrm{N})$.

The calibration results are shown in Figure 9. As can be seen, the piecewise function

216 characterizes the Young's modulus and unconfined compressive strength for both high-moisture

217 content domain and low-moisture content domain with a good accuracy. These calibrated 218 parameters, together with the particle scaling factor $\alpha_{w}$, have been used in the following 219 modeling of desiccation cracking.

Numerical modeling of desiccation cracking

223 Mono-sized spherical particles with a diameter of $1.0 \mathrm{~mm}$ are generated inside a petri dish. The 224 dish has an inner diameter of $8.0 \mathrm{~cm}$ and a thickness of $0.75 \mathrm{~cm}$, as is shown in Figure 10. 225 Totally 65,012 particles have been generated and balanced under gravity, and the equilibrium 226 porosity is 0.433 . A fixed ball boundary has been used on the outer layer of the bentonite sample 
227 (Figure 10), and boundary particles with diameter $0.6 \mathrm{~mm}$ remain fixed during the simulation.

228 Contacts between boundary particles and regular particles are the same as is given in Figure 6.

229 The desiccation process of the bentonite clay is simulated based on the losses of soil

230 moisture. The gravimetric water content of soil sample decreases from an initial value of $425 \%$

231 to the residual water content of $7 \%$. Particle size and contact parameters are assigned according

232 to the gravimetric water content as calibrated above. Considering the discontinuity of the clay-

233 dish interface, particles contacting with the ball boundary have a strength reduction on bond

234 strength and frictional coefficient, while the contact stiffness remains the same, as provided in

235 Eqs. (5-7).

$K_{n / s, c}=K_{n / s}$

$\sigma_{n / s, c}=\beta \sigma_{n / s}$

$f_{c}=\beta f$

236 where $K_{n / s, c}$ is the normal/tangential spring stiffness of particles contacting with dish surface

$237(\mathrm{~N} / \mathrm{m}) ; \sigma_{n / s, c}$ is the normal/tangential adhesive strength of particles contacting with dish surface

$238(\mathrm{~N}) ; f_{c}$ is the frictional coefficient of particles contacting with dish surface; $\beta$ is the strength

239 reduction factor. The strength reduction factor $\beta$ is assumed to be 0.0 in this simulation case. Its

240 influence on simulation results has been discussed below in details.

241 The simulation result together with the laboratory experiment are shown in Figure 11. In

242 the laboratory experiment, a thin layer of 0.6-mm-diameter Nevada sand was coated on the petri

243 dish surface to emulate the boundary condition applied in the DEM model. From Figure 11, a

244 high consistency is observed between the numerical model and the laboratory experiment in

245 terms of crack initiation and propagation. The first crack occurred near the weak interface

246 between clay and petri dish $(w=300 \%)$. Then major cracks generated and cut the sample into 
247 five to six large polygons $(w=200 \%)$. Minor cracks were also generated subsequently as the 248 sample dried further, which however do not change the final frack patterns.

\section{Influence of bottom constraint}

252 The final crack patterns of bentonite under different surface roughness have been compared through experiments and simulations. The experimental comparison was prepared by coating a petri dish with two types of Nevada sands with mean grain sizes of $0.6 \mathrm{~mm}$ and $1.0 \mathrm{~mm}$. The different surface roughness in the DEM model is simulated through generating different sized boundary particles $(0.6 \mathrm{~mm}$ and $1.0 \mathrm{~mm})$, as is shown in Figure 12 . Other model parameters are the same as discussed previously. The initial sample thickness is $0.75 \mathrm{~cm}$ in both the numerical model and the laboratory experiment.

The final crack patterns of the experiments and simulations are given in Figure 13. As 260 the surface roughness increases, bentonite clay cracks intensively, and the number of the crack 261 polygons increases. Both the DEM model and laboratory experiment show the bottom roughness

262 has a significant influence on the final crack patterns. A rougher surface provides a larger bottom 263 resistance and generates a higher internal stress, which finally leads to more tensile cracks under 264 the same condition.

The strength reduction factor $\beta$, which describes the discontinuity between clay and dish

266 surface, changes with soil water content and is difficult to measure directly. A sensitivity study 267 on $\beta$ was conducted in order to better analyze its influence. The initial sample thickness is 0.75 $268 \mathrm{~cm}$ and the sand grains coated on the dish surface are $0.6 \mathrm{~mm}$ in diameter. A reduction factor of 2690.0 indicates that there is no particle-level bond strength and friction on the dish surface. A 
270 reduction factor of 1.0 indicates the particle-level bond strength and frictional coefficient on the

271 interface are the same as the inner clay particles. It should be noted that even with a reduction

272 factor of 0.0 , the rough surface still offers frictional resistance to the clay sample in the

273 macroscale. The modeling results are given in Figure 14. Soil sample with a low bottom

274 strength (or small $\beta$ value) tends to shrinkage toward the center and is more intact at the residual

275 water content. Compared with the experimental observations, a strength reduction factor of 0.0

276 was used in this paper as the baseline simulation.

277

Influence of sample thickness

280 The final crack patterns of bentonite with different initial sample thickness are compared 281 between experiment and simulation. Three different sample thicknesses are analyzed, including $2820.50 \mathrm{~cm}, 0.75 \mathrm{~cm}$ and $1.00 \mathrm{~cm}$. The petri dish has been coated with $0.6-\mathrm{mm}$-diameter sand 283 grains. Other parameters used in the DEM model are the same as previously discussed. The 284 comparison between numerical model and laboratory experiment is given in Figure 15. Overall 285 the DEM model replicates the laboratory observations well. For a thinner bentonite layer, the 286 bottom constraint has a considerable influence on its shrinkage cracking, and the crack intensity 287 (crack length per unit area) is much higher than the thicker sample.

289 has a significant influence on crack initiation and propagation (Nahlawi and Kodikara 2006; 290 Tang 2011a). The non-uniform vertical moisture distribution and the higher surface energy 291 required to generate crack for thicker samples are two possible explanations. In this model, 292 moisture content of the bentonite layer is assumed to be the same throughout the sample, and the 
293 non-uniform moisture distribution is not considered. However this DEM model replicates

294 different crack patterns well, which may imply surface energy should play a more important role

295 in the formation of desiccation cracking under this laboratory condition.

297 Conclusions

299 The desiccation cracking behavior of a thin bentonite layer has been studied through laboratory 300 experiment and numerical modeling. A custom-built monitoring system was set up to evaluate 301 the shrinkage behaviors of bentonite under controlled temperature and humidity conditions. To 302 better estimate the shrinkage volume of bentonite clay, a hydrophobic coating was applied on the 303 petri dish surface to diminish the bottom constraint and prevent cracking and curling of soil 304 sample. The image analysis was used together with the sample thickness measurement to obtain 305 the volumetric strain of bentonite at different moisture contents.

A DEM model is built to simulate the shrinking process of a thin bentonite layer under

307 laboratory conditions. This DEM model is based on two major assumptions: 1) shrinkage of 308 bentonite clay can be described at the aggregate level; 2) mechanical properties of the clay 309 aggregates vary with the moisture content. Based on these assumptions, particle size in the DEM 310 model is scaled according to the measured volumetric strain at different water content. Contact 311 parameters of the DEM model, including particle stiffness, bond strength and frictional 312 coefficient, are calibrated through a series of unconfined compression tests of bentonite

313 specimens with different water contents. Using the calibrated parameters, the drying process of 314 bentonite with different bottom constraint and thickness are simulated. The numerical model 315 shows a high consistency with the laboratory experiment, proving its capability to predict the 
316 formation of desiccation cracks of bentonite clay.

317 The experiments show that major cracks are firstly formed and dominate the shape of 318 crack polygons; minor cracks are formed subsequently as the clay dries further and cuts the 319 sample into smaller polygons. The numerical model replicates reasonably well the generation of 320 major and minor cracks. Both the experiment and numerical model demonstrate that the 321 formation of desiccation cracks is highly sensitive to the boundary constraints, including the 322 surface roughness and surface strength, and sample thickness. Drying thinner samples on a 323 tougher and more adhesive surface tends to produce more cracks. The simulation also indicates 324 that the pattern of desiccation cracks of the thin bentonite layer appears to be mainly dominated 325 by the shrinkage process rather than the non-uniform moisture distribution. Besides improving 326 material strength, reducing boundary constraint also has the benefits in the control of desiccation 327 cracks of bentonite.

328 This paper demonstrates the procedures for model building and calibration to holistically 329 simulate the process of crack initialization. Note that the water evaporation rate is only 330 heuristically considered in this work by use of monitored evaporation data, details of which 331 might have important effects on the crack development processes, e.g., distribution of soil 332 moisture, ambient temperature and humidity. This will need to be analyzed by building a more 333 advanced model, for example, by possibly coupling with a continuous model that describes 334 moisture exchange across the boundaries. 


\section{REFERENCES}

Albrecht, B.A., and Benson, C.H. Effect of Desiccation of Compacted Natural Clays. Journal of Geotechnical and Geoenvironmental Engineering, Vol. 127, No. 1, 2001, pp. 67-75.

Amarasiri, A.L., Kodikara, J.K., and Costa, S. 2011. Numerical Modelling of Desiccation Cracking. International Journal for Numerical and Analytical Methods in Geomechanics, Vol. 35, No. 1, pp. $82-96$.

Amarisiri, A., Shannon, B., and Kodikara, J. 2014. Numerical Modelling of Desiccation Cracking in a Restrained Ring Test. Canadian Geotechnical Journal Vol. 51, No. 1, pp. 67-76.

ASTM D4318-00. 2000. Standard Test Methods for Liquid Limit, Plastic Limit, and Plasticity Index of Soils. ASTM International, United States.

ASTM D2166/D2166M-13. 2013. Standard Test Method for Unconfined Compressive Strength of Cohesive Soil. ASTM International, United States.

Bagherieh, A.R., Khalili, N., Habibagahi, G., and Ghahramani, A. 2009. Drying Response and Effective Stress in a Double Porosity Aggregated Soil. Engineering Geology, Vol. 105, pp. 44-50.

Borgesson, L., Chijimatsu, M., Fujita, T., Nguyen, T.S., Rutqvist, J., and Jing, L. 2001. Thermo-HydroMechanical Characterisation of a Bentonite-Based Buffer Material by Laboratory Tests and Numerical Back Analyses. International Journal of Rock Mechanics \& Mining Sciences, Vol. 38, pp. 95-104.

Byun, Y.H., Lee, J.S., Cho, S.H., and Yoon, H.K. 2013. Evaluation of Void Ratio and Elastic Modulus of Unsaturated Soil Using Elastic Waves. Proceedings of the 18th International Conference on Soil Mechanics and Geotechnical Engineering, Paris, pp. 1089-1092.

Daniel, D., and Wu, Y.K. 1993. Compacted Clay Liners and Covers for Arid Sites. The Journal of Geotechnical Engineering, Vol. 119, No. 2, pp. 223-237.

Dyer, M., Utili, S., and Zielinski, M. 2007. The Influence of Desiccation Fine Fissuring on the Stability of Flood Embankment, FRMRC Research Report UR11. 
362

363

364

365

366

367

El Maarry, M.R., Watters, W.A., Yoldi, Z., Pommerol, A., Fischer, D., Eggenberger, U., and Thomas, N. 2015. Field Investigation of Dried Lakes in Western United States as an Analogue to Desiccation Fractures on Mars. Journal of Geophysical Research: Planets, Vol. 120, No. 12, 2241-2257.

El Youssoufi, M.S., Delenne, J.Y., and Radjai, F. 2005. Self-Stresses and Crack Formation by Particle Swelling In Cohesive Granular Media. Physical Review E, Vol. 71, No. 5, pp. 1-5.

Gebrenegus, T., Ghezzehei, T.A., and Tuller, M. 2011. Physicochemical Controls on Initiation and Evolution of Desiccation Cracks in Sand-Bentonite Mixtures: X-Ray CT Imaging and Stochastic Modeling. Journal of contaminant hydrology. Vol. 126 pp. 100-112.

Gui, Y., and Zhao, G.F. 2015. Modelling of Laboratory Soil Desiccation Cracking using DLSM with a Two-Phase Bond Model. Computers and Geotechnics, Vol. 69 pp. 578-587.

Gui, Y.L., Zhao, Z.Y., Kodikara, J., Bui, H.H., and Yang, S.Q. 2016. Numerical Modelling of Laboratory Soil Desiccation Cracking using UDEC with a Mix-Mode Cohesive Fracture Model. Engineering Geology, Vol. 202 pp. 14-23.

Hedan, S., Fauchille, A.L., Valle, V., Cabrera, J., and Cosenza, P. 2014. One-Year Monitoring of Desiccation Cracks in Tournemire Argillite using Digital Image Correlation. International Journal of Rock Mechanics and Mining Sciences, Vol. 68 pp. 22-35.

Hirobe, S., and Oguni, K. 2016. Coupling Analysis of Pattern Formation in Desiccation Cracks. Computer Methods in Applied Mechanics and Engineering - accepted manuscript.

Kakuturu, S., and Reddi, L. 2006. Evaluation of the Parameters Influencing Self-Healing in Earth Dams. Journal of Geotechnical and Geoenvironmental Engineering Vol. 132, No. 7 pp. 879-889.

Kalkan, E. 2009. Influence of Silica Fume on the Desiccation Cracks of Compacted Clayey Soils. Applied Clay Science, Vol. 43, No. 3-4, pp. 296-302.

Katti, D., Matar, M.I., Katti, K.S., and Amarasinghe, P.M. 2009. Multiscale Modeling of Swelling Clays: A Computational and Experimental Approach. KSCE Journal of Civil Engineering, Vol. 13, No. 4, pp. 243-255.

Kodikara, J., and Chakrabarti, S. 2005. Modeling of Moisture Loss in Cementitiously Stabilized 
Pavement Materials. International Journal of Geomechanics, Vol. 5, No. 4, pp. 295-303.

Anderson, M., and Lu, N. 2001. Role of Microscopic Physicochemical Forces in Large Volumetric Strains for Clay Sediments. Journal of Engineering Mechanics, Vol. 127, No. 7, pp. 710-719.

Liu, C., Pollard, D., and Shi, B. 2013. Analytical Solutions and Numerical Tests of Elastic and Failure Behaviors of Close-Packed Lattice for Brittle Rocks and Crystals. Journal of Geophysical Research: Solid Earth, Vol. 118, pp. 71-82.

Lu, N., and Kaya, M. 2013. A Drying Cake Method for Measuring Suction-Stress Characteristic Curve, Soil-Water-Retention Curve, and Hydraulic Conductivity Function. Geotechnical Testing Journal, Vol. 36, No. 1, pp. 1-19.

Lu, Y., Liu, S., Weng, L., Wang, L., Li, Z., and Xu, L. 2016. Fractal Analysis of Cracking in a Clayey Soil under Freeze-Thaw Cycles. Engineering Geology, Vol. 208, pp. 93-99.

Morris, P.H., Graham, J., and Williams, D.J. 1992. Cracking in Drying Soils. Canadian Geotechnical Journal, Vol. 29, No. 2, pp. 263-277.

Nahlawi, H., and Kodikara, J.K. 2006. Laboratory Experiments on Desiccation Cracking of Thin Soil Layers. Geotechnical and Geological Engineering, Vol. 24, No. 6, pp. 1641-1664.

Pelot, D.D., Jun, S., and Yarin, A.L. 2015. Bentonite Dispersions: Transition from Liquid-Like to SolidLike Behavior and Cracking. Journal of Non-Newtonian Fluid Mechanics, Vol. 219, pp. 50-64.

Peron, H., Hueckel, T., Laloui, L., and Hu, L.B. 2009a. Fundamentals of Desiccation Cracking of FineGrained Soils: Experimental Characterisation and Mechanisms Identification. Canadian Geotechnical Journal, Vol. 46, No. 10, pp. 1177-1201.

Peron, H., Delenne, J.Y., Laloui, L., and El Youssoufi, M.S. 2009b. Discrete Element Modelling of Drying Shrinkage and Cracking of Soils. Computers and Geotechnics, Vol. 36, pp. 61-69.

Rayhani, M.H.T., Yanful, E.K., and Fakher, A. 2008. Physical Modeling of Desiccation Cracking in Plastic Soils. Engineering Geology, Vol. 97, pp. 25-31.

Rodríguez, R., Sánchez, M., Ledesma, A., and Lloret, A. 2007. Experimental and Numerical Analysis of Desiccation of a Mining Waste. Canadian Geotechnical Journal, Vol. 44, No. 6, pp. 644-658. 
414 Santamarina, J. C. 2001. Soil Behavior at the Microscale: Particle Forces. Proceedings of the Symposium on Soil Behavior and Soft Ground Construction.

Sánchez, M., Manzoli, O.L., and Guimarães, L.J.N. 2014. Modeling 3-D Desiccation Soil Crack Networks using a Mesh Fragmentation Technique. Computers and Geotechnics, Vol. 62, pp. 27-

Shokri, N., Zhou, P., and Keshmiri, A. 2015. Patterns of Desiccation Cracks in Saline Bentonite Layers. Transport in Porous Media, Vol. 110, No. 2, pp. 333-344.

Sima, J., Jiang, M., and Zhou, C. 2014. Numerical Simulation of Desiccation Cracking in a Thin Clay Layer using 3D Discrete Element Modeling. Computers and Geotechnics, Vol. 56, pp. 168-180.

Stirling, R.A., Hughes, P., Davie, C.T., and Glendinning, S. 2015. Tensile Behaviour of Unsaturated Compacted Clay Soils-A Direct Assessment Method. Applied Clay Science, Vol. 112-113, pp. $123-133$.

Tang, C., Shi, B., Liu, C., Zhao, L., and Wang, B. 2008. Influencing Factors of Geometrical Structure of Surface Shrinkage Cracks in Clayey Soils. Engineering Geology, Vol. 101, pp. 204-217.

Tang, C., Cui, Y., Tang, A., and Shi, B. 2010. Experiment Evidence on the Temperature Dependence of Desiccation Cracking Behavior of Clayey Soils. Engineering Geology, Vol. 114, pp. 261-266. and Desiccation Cracking in Thin Clay Layer. Applied Clay Science, Vol. 52, pp. 69-77.

Tang, C.S., Cui, Y.J., Shi, B., Tang, A.M., and Liu, C. 2011b. Desiccation and Cracking Behaviour of Clay Layer from Slurry State under Wetting-Drying Cycles. Geoderma, Vol. 166, pp. 111-118.

Tisato, N., and Marelli, S. 2013. Laboratory Measurements of the Longitudinal and Transverse Wave Velocities of Compacted Bentonite as a Function of Water Content, Temperature, and Confining Pressure. Journal of Geophysical Research: Solid Earth, Vol. 118, No. 7, pp. 3380-3393.

Utili, S. 2013. Investigation by Limit Analysis on the Stability of Slopes with Cracks. Géotechnique, Vol. 63, No. 2, pp. 140-154.

Villar, M.V. 2005. MX-80 Bentonite Thermo-Hydro-Mechanical Characterisation Performed at CIEMAT 

in the Context of the Prototype Project, pp. 1-39.

441 Wang, Y., and Mora, P. 2008. Macroscopic Elastic Properties of Regular Lattices. Journal of the 442 Mechanics and Physics of Solids, Vol. 56, pp. 3459-3474.

443 Yesiller, N., Miller, C.J., Inci, G., and Yaldo, K. 2000. Desiccation and Cracking Behavior of Three 444 Compacted Landfill Liner Soils. Engineering Geology, Vol. 57, pp. 105-121.

445 Zielinski, M., Sánchez, M., Romero, E., and Atique, A. 2014. Precise Observation of Soil Surface 446 Curling. Geoderma, Vol. 226-227, pp. 85-93.

447 
$448 \quad$ List of Figures:

449 Figure 1. Experimental setup of custom-built crack monitoring system.

450 Figure 2. Drying process of a thin bentonite layer in a coated petri dish (thickness $=0.75 \mathrm{~cm}$ ).

451 Figure 3. Comparison of final crack patterns in uncoated and coated dishes (thickness $=0.75 \mathrm{~cm}$, $w=7 \%)$.

453 Figure 4. Gravimetric water content of bentonite clay over time.

454 Figure 5. Volumetric strain of bentonite clay during drying.

$455 \quad$ Figure 6. Contact models between two spherical particles.

456 Figure 7. Comparison of shear plane angles between experiment and simulation under unconfined compression test.

Figure 8. Regression of particle parameters of the DEM model: (a) particle spring stiffness; (b) particle bond strength.

Figure 9. Calibration results of the DEM model: (a) the Young's modulus; (b) unconfined compressive strength.

462 Figure 10. Dimensions of the DEM desiccation cracking model.

463 Figure 11. Comparison between laboratory experiment and numerical simulation of desiccation cracking (thickness $=0.75 \mathrm{~cm}, \beta=0.0, d_{\text {sand }}=0.6 \mathrm{~mm}$ ).

Figure 12. The DEM models with different surface roughness (coated with different sand layers).

67 Figure 13. Comparison of final crack patterns of bentonites with different surface roughness (thickness $=0.75 \mathrm{~cm}, \beta=0.0$ )

469 Figure 14. Final crack patterns of bentonites with different surface strength reduction factors 470

$$
\text { (thickness } \left.=0.75 \mathrm{~cm}, d_{\text {sand }}=0.6 \mathrm{~mm}\right) \text {. }
$$


471 Figure 15. Comparison of final crack patterns of bentonites with different thicknesses $(\beta=0.0$,

472 $\left.d_{\text {sand }}=0.6 \mathrm{~mm}\right)$.

473 


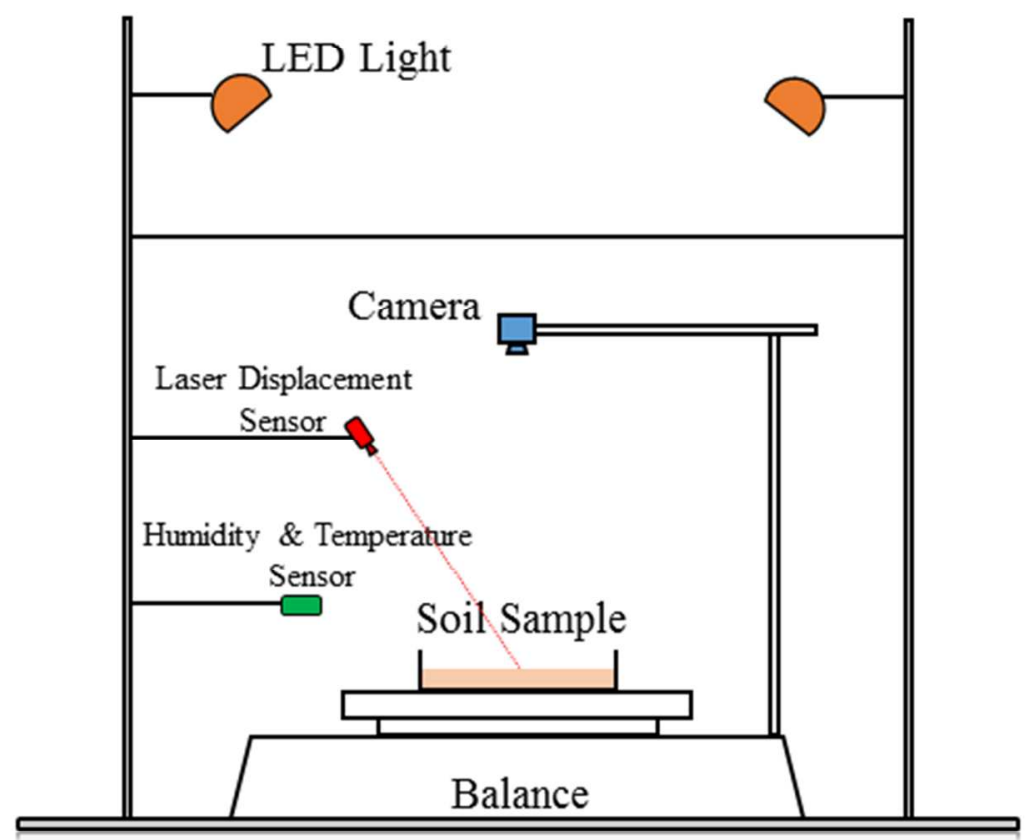

1

Figure 1. Experimental setup of custom-built crack monitoring system. 

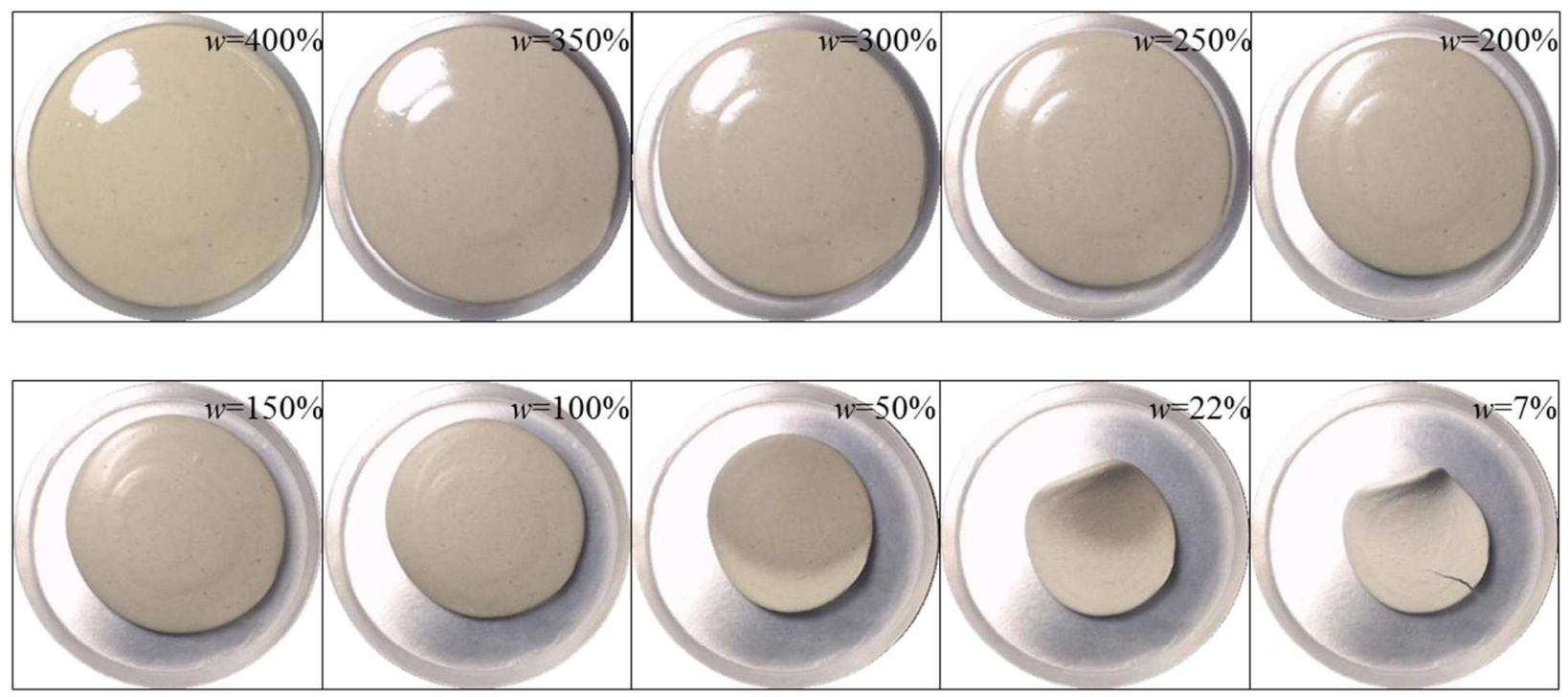

4

5 Figure 2. Drying process of a thin bentonite layer in a coated petri dish (thickness $=0.75 \mathrm{~cm}$ ). 

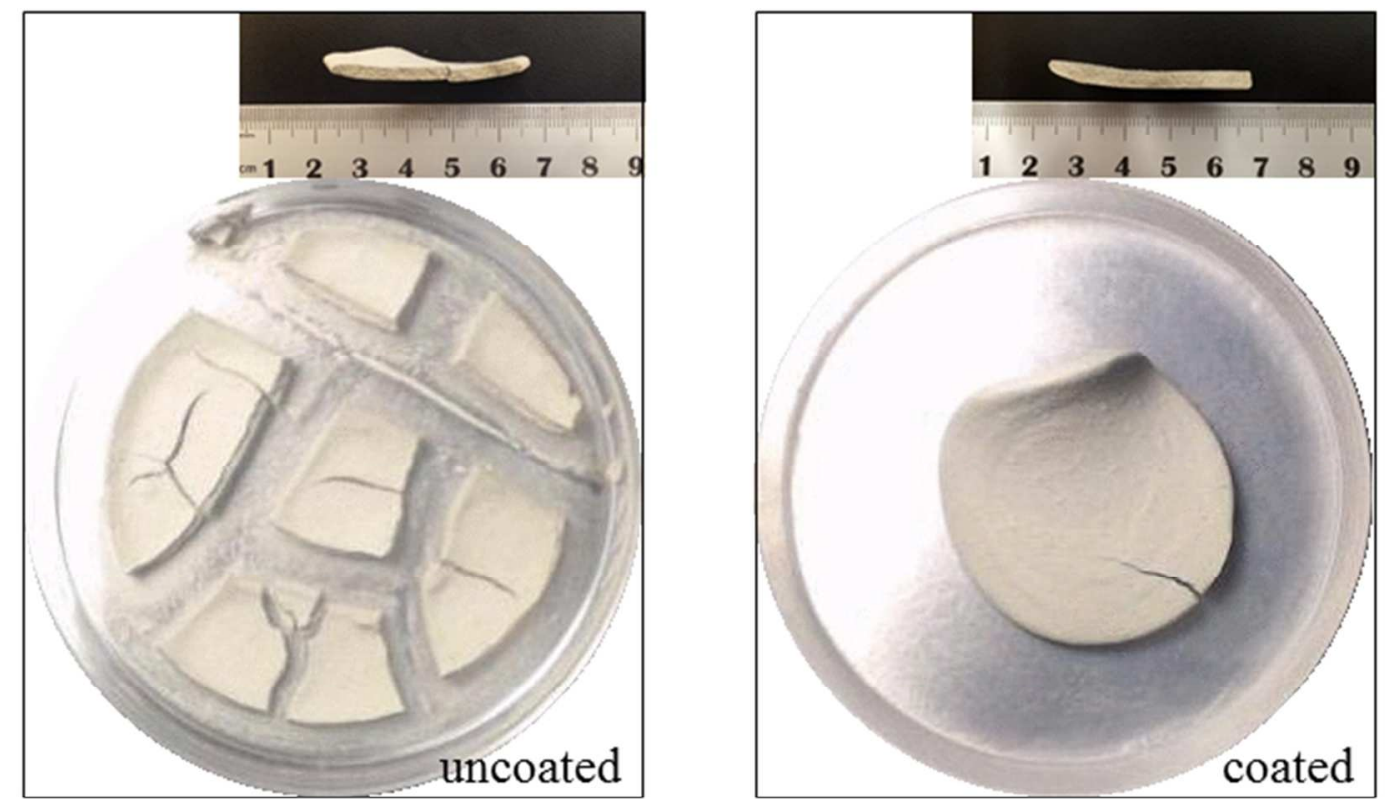

7

8 Figure 3. Comparison of final crack patterns in uncoated and coated dishes (thickness $=0.75 \mathrm{~cm}$, 9 $w=7 \%)$ 


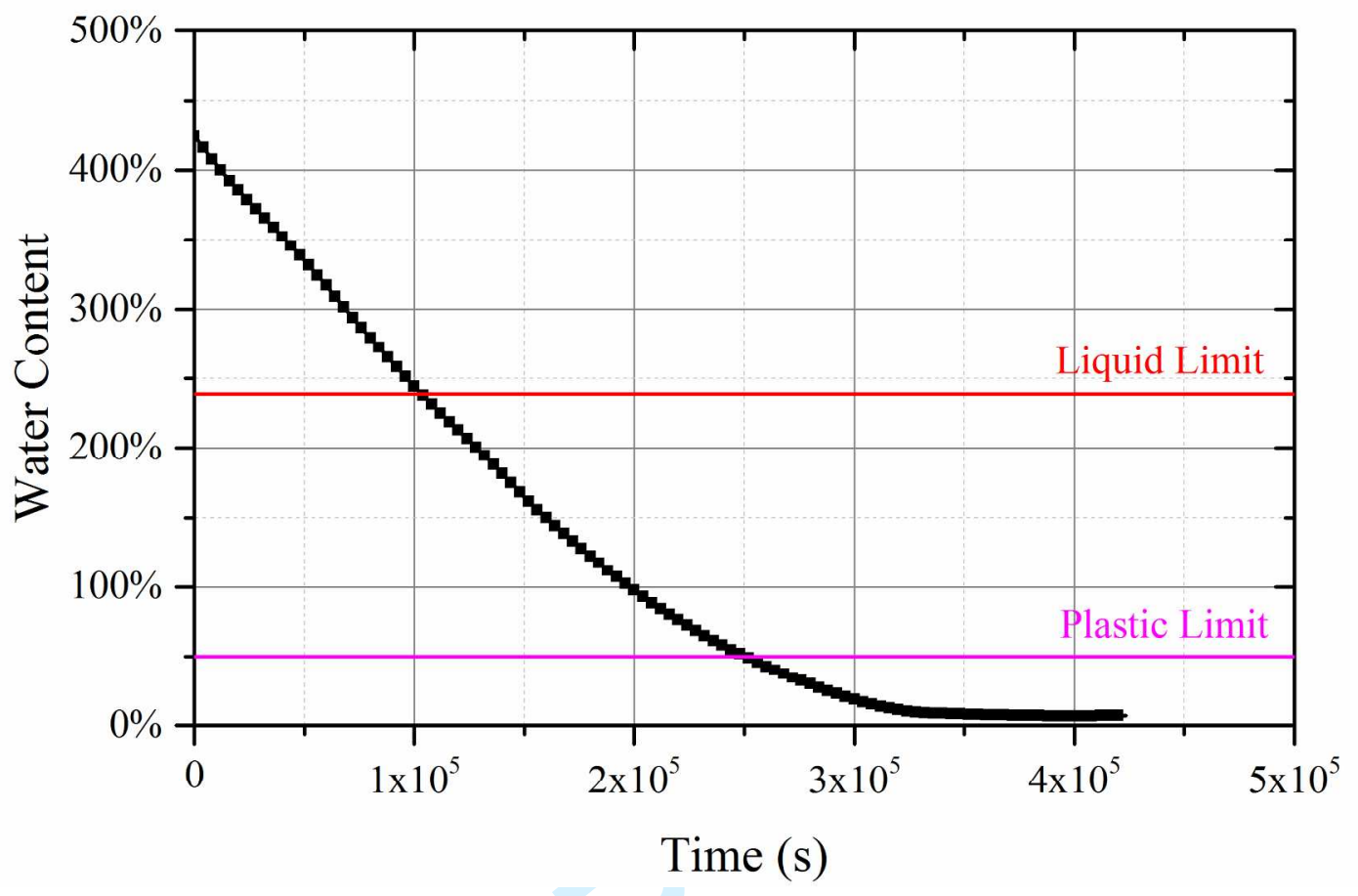

Figure 4. Gravimetric water content of bentonite clay over time. 


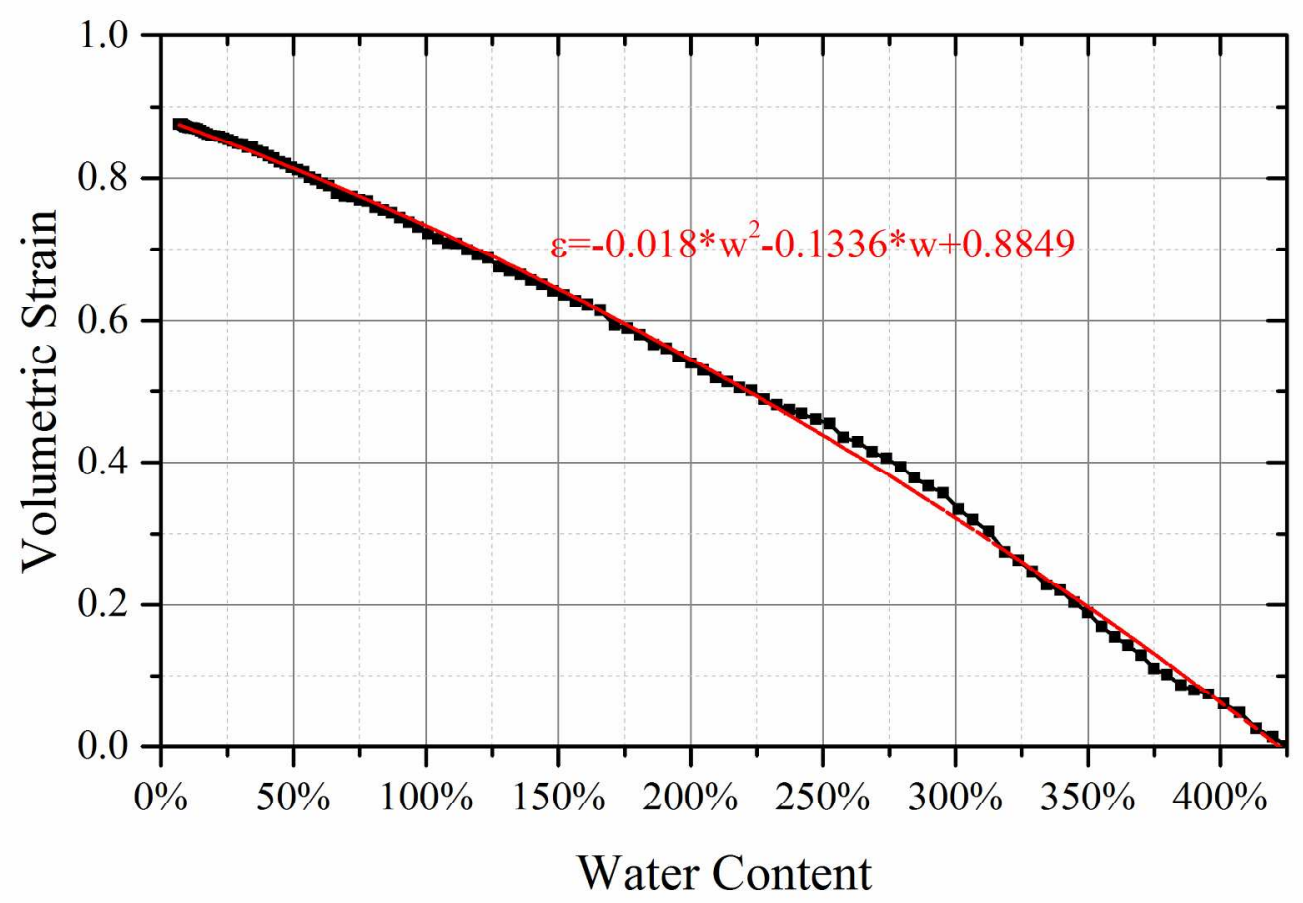

14 Figure 5. Volumetric strain of bentonite clay during drying. 


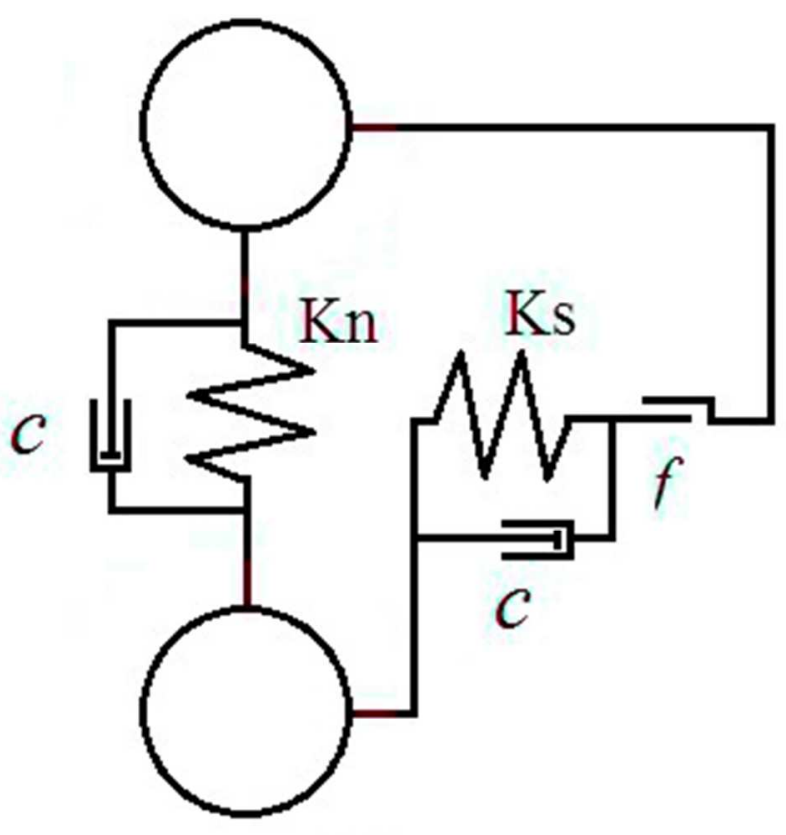

17

Figure 6. Contact models between two spherical particles.

19 


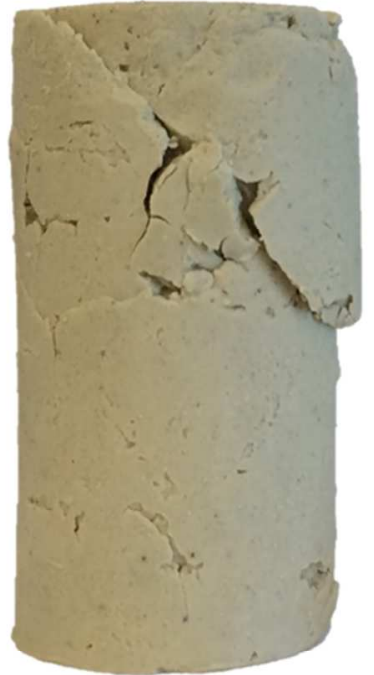

20

21

22

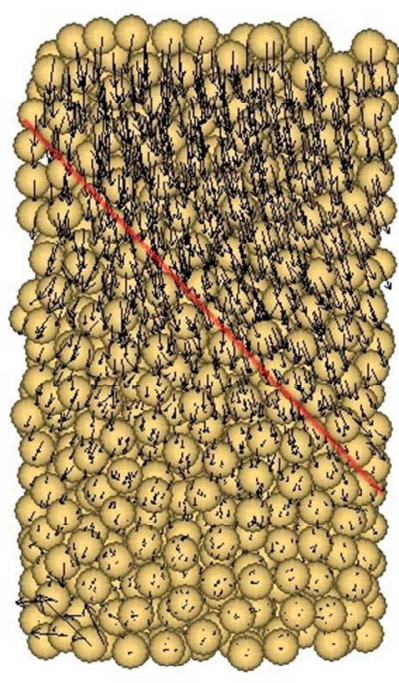

Particle Velocity $\longmapsto 0.02 \mathrm{~mm} / \mathrm{s}$

Figure 7. Comparison of shear plane angles between experiment and simulation under unconfined compression test. 


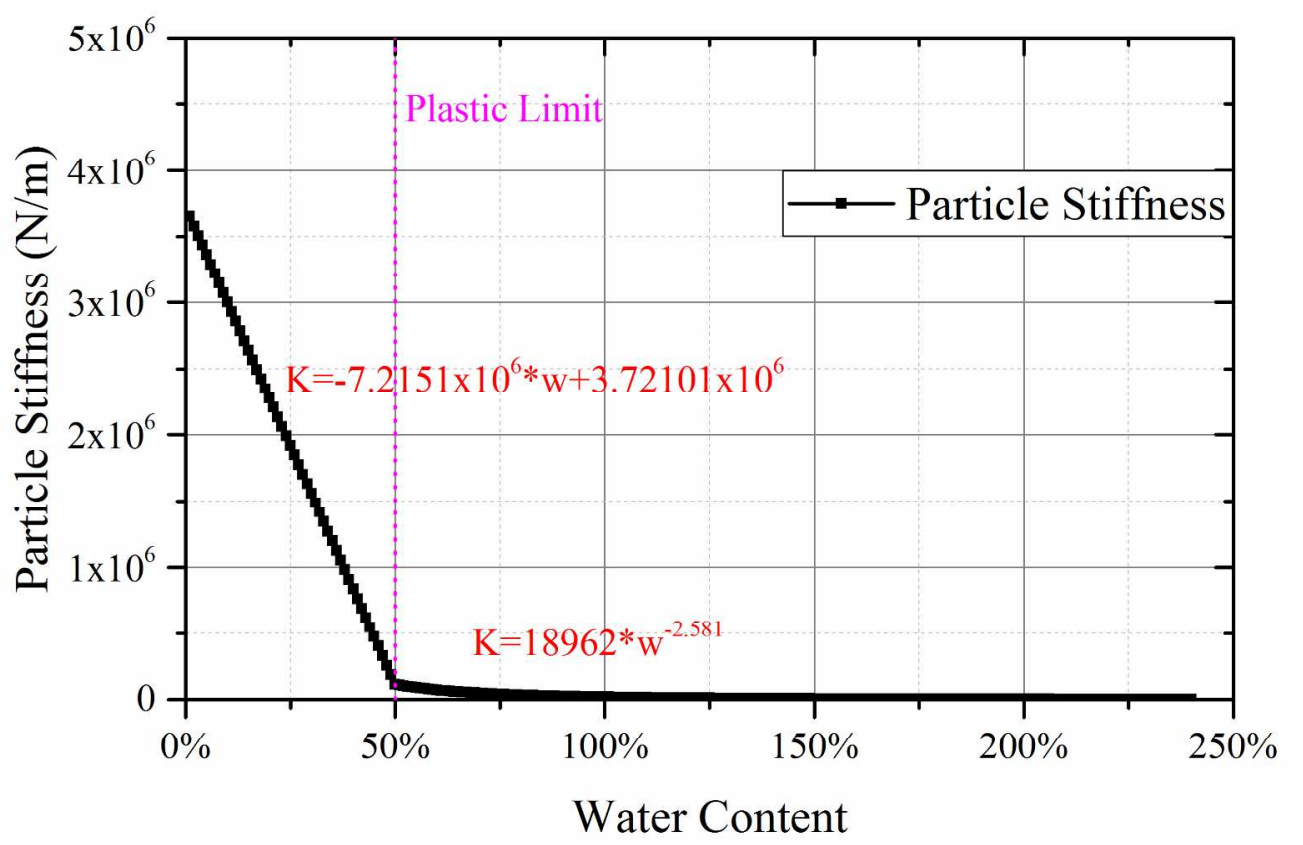

(a) Particle spring stiffness

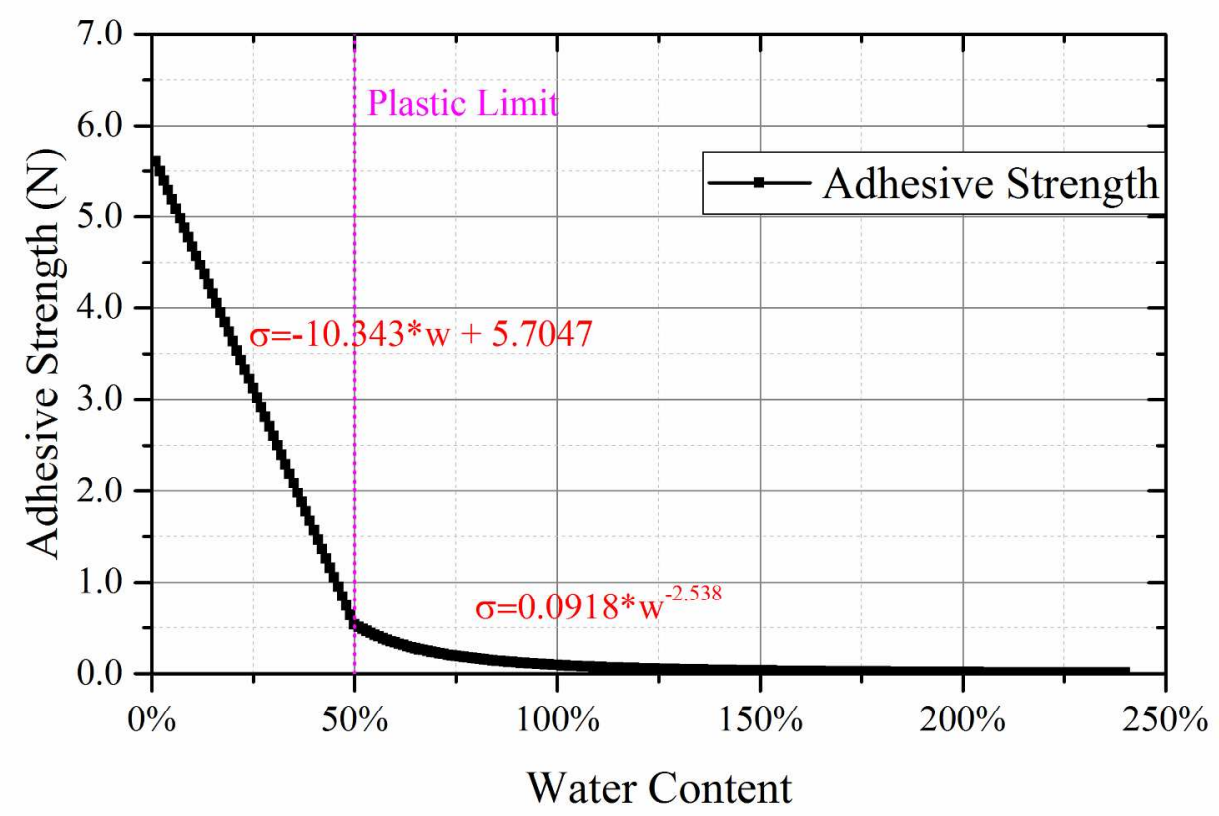

(b) Particle bond strength

27 Figure 8. Regression of particle parameters of the DEM model: (a) particle spring stiffness; (b) particle bond strength. 
29

30

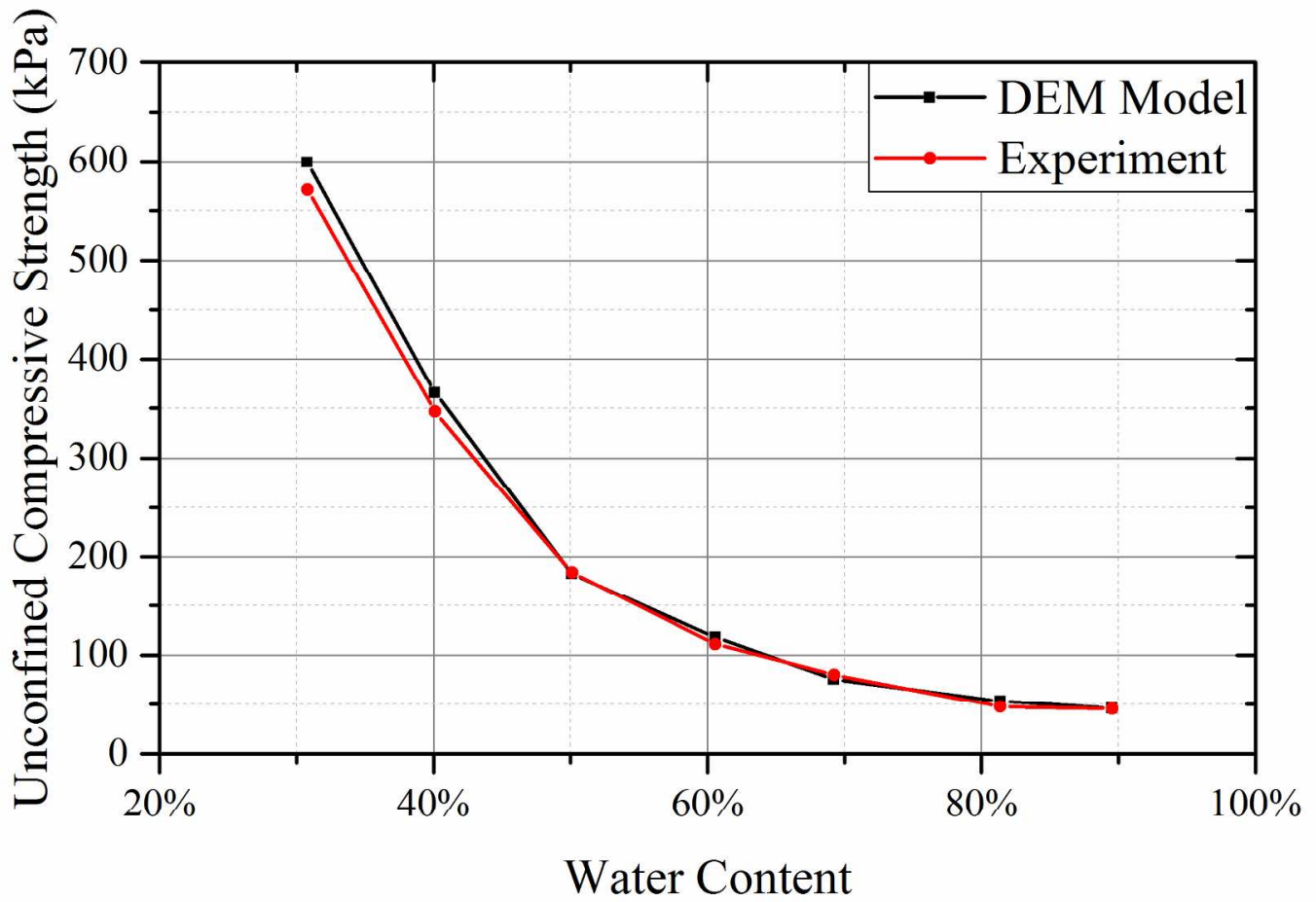

(a) The Young's modulus

\section{Water Content}

(b) Unconfined compressive strength

Figure 9. Calibration results of the DEM model: (a) the Young's modulus; (b) unconfined compressive strength.

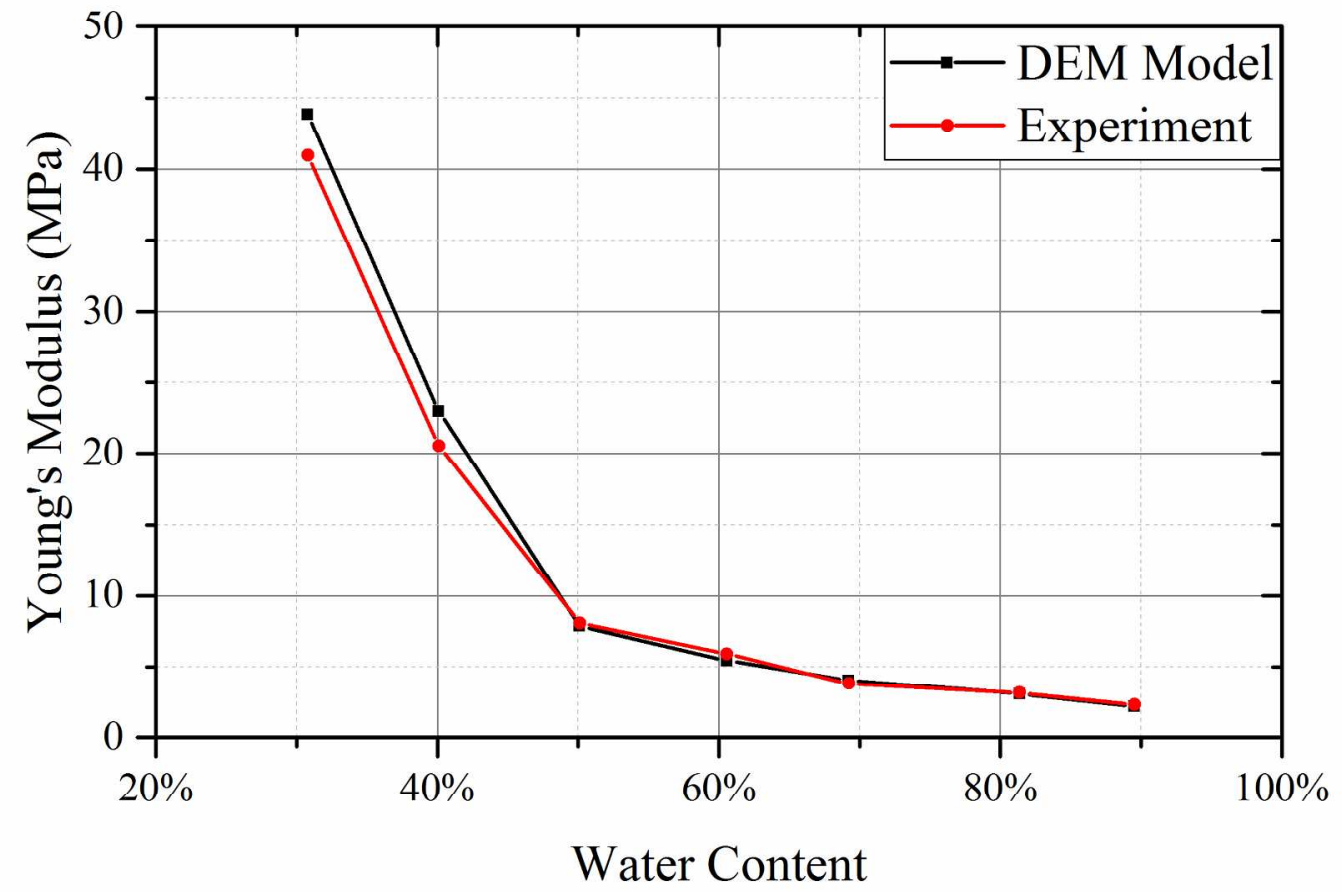




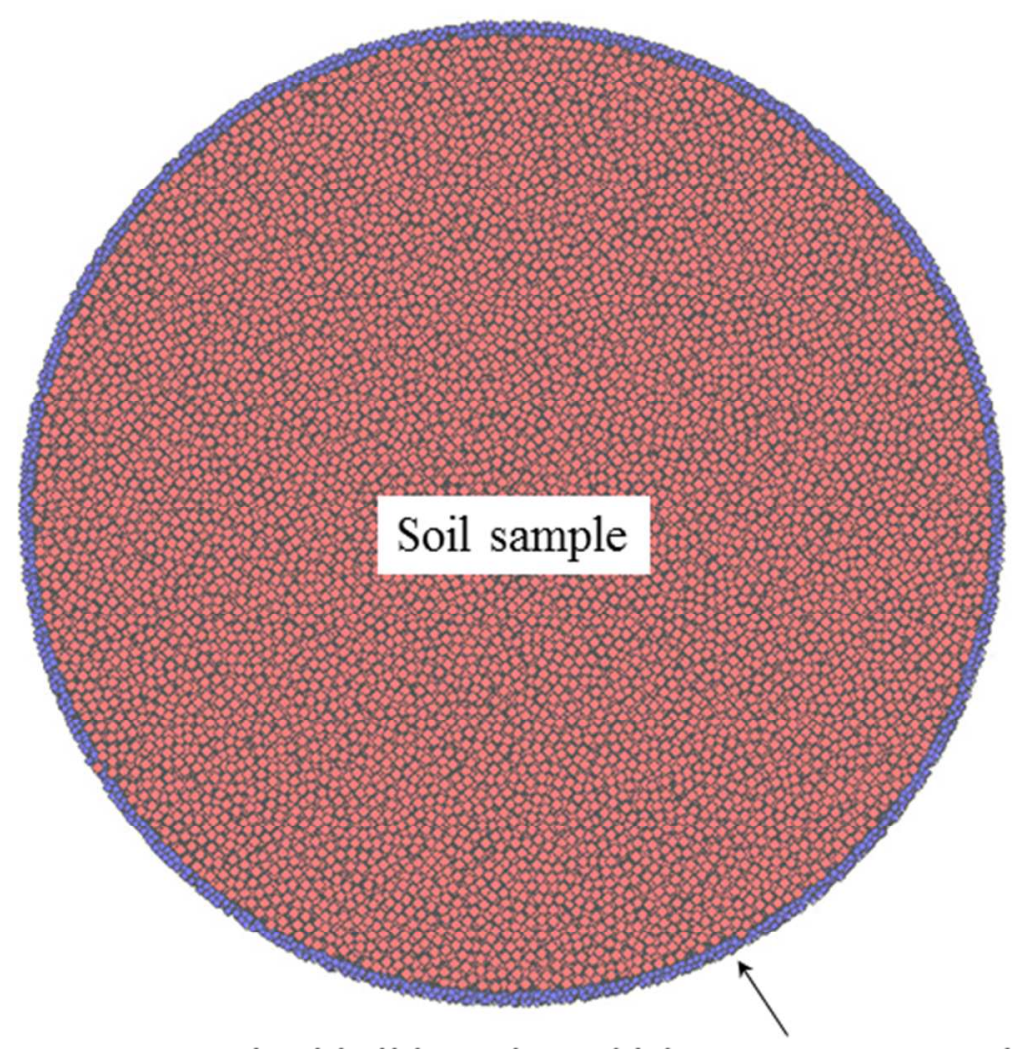

Fixed ball boundary, thickness $=1.0 \mathrm{~mm}$, particle diameter $=0.6 \mathrm{~mm}$

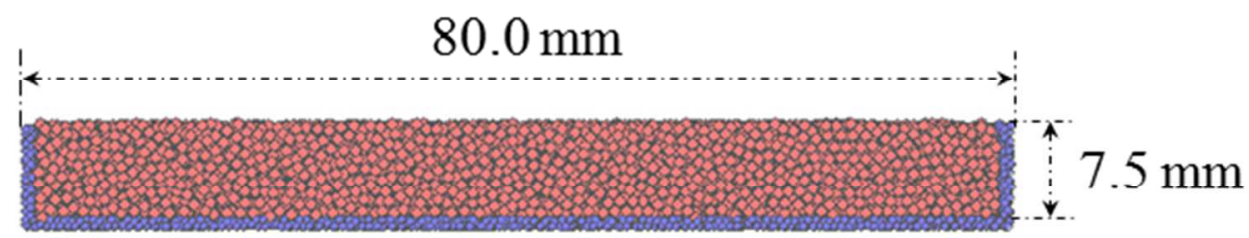

Figure 10. Dimensions of the DEM desiccation cracking model. 

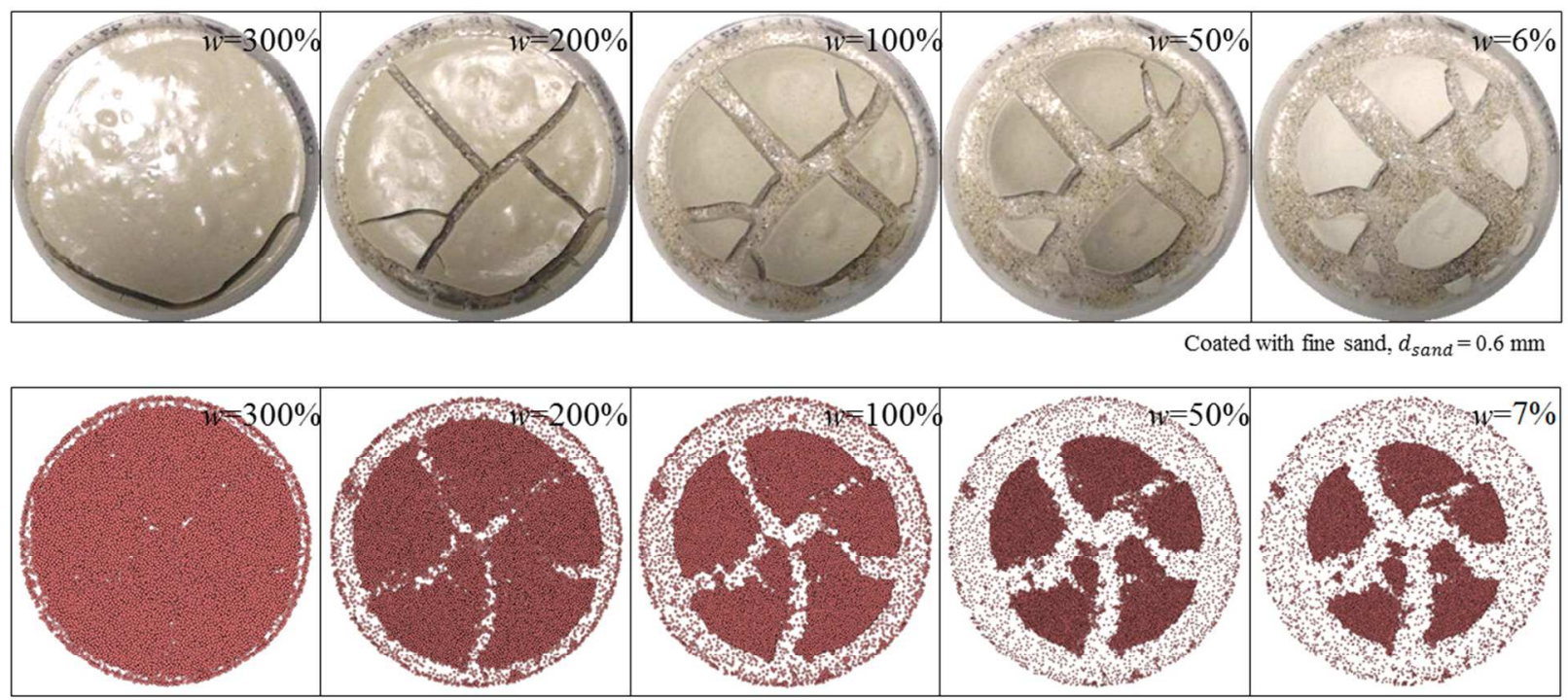

40

41 Figure 11. Comparison between laboratory experiment and numerical simulation of desiccation cracking (thickness $=0.75 \mathrm{~cm}, \beta=0.0, d_{\text {sand }}=0.6 \mathrm{~mm}$ ). 

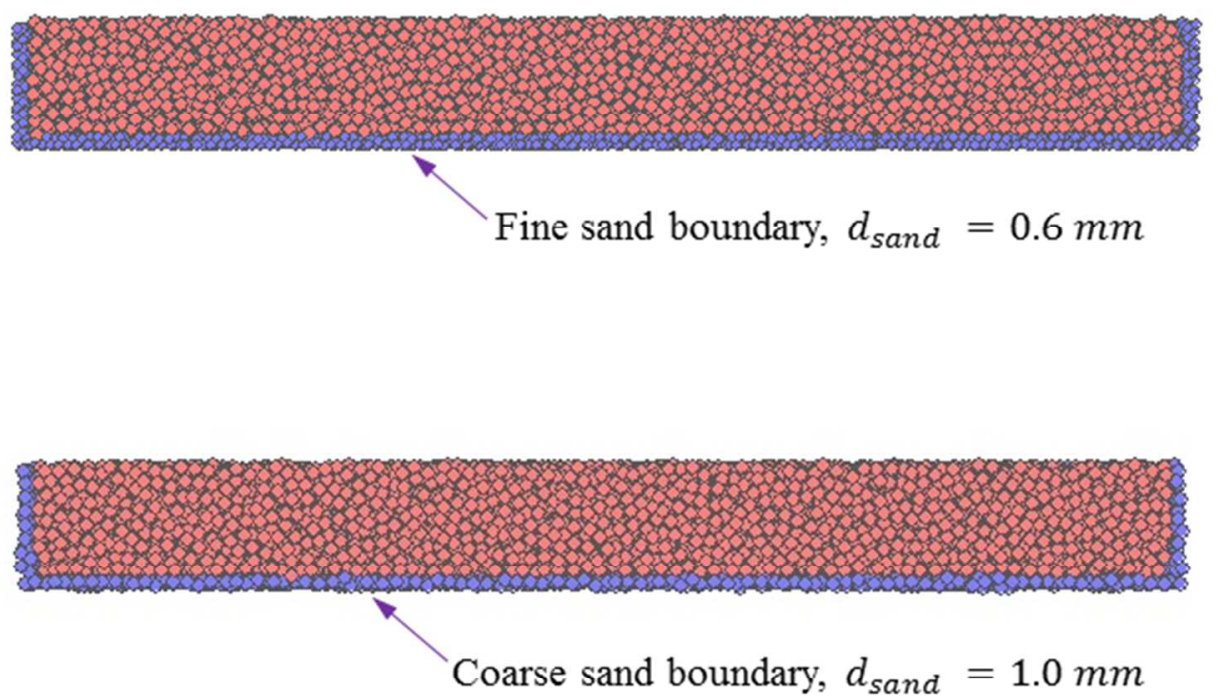

44

Figure 12. The DEM models with different surface roughness (coated with different sand layers). 


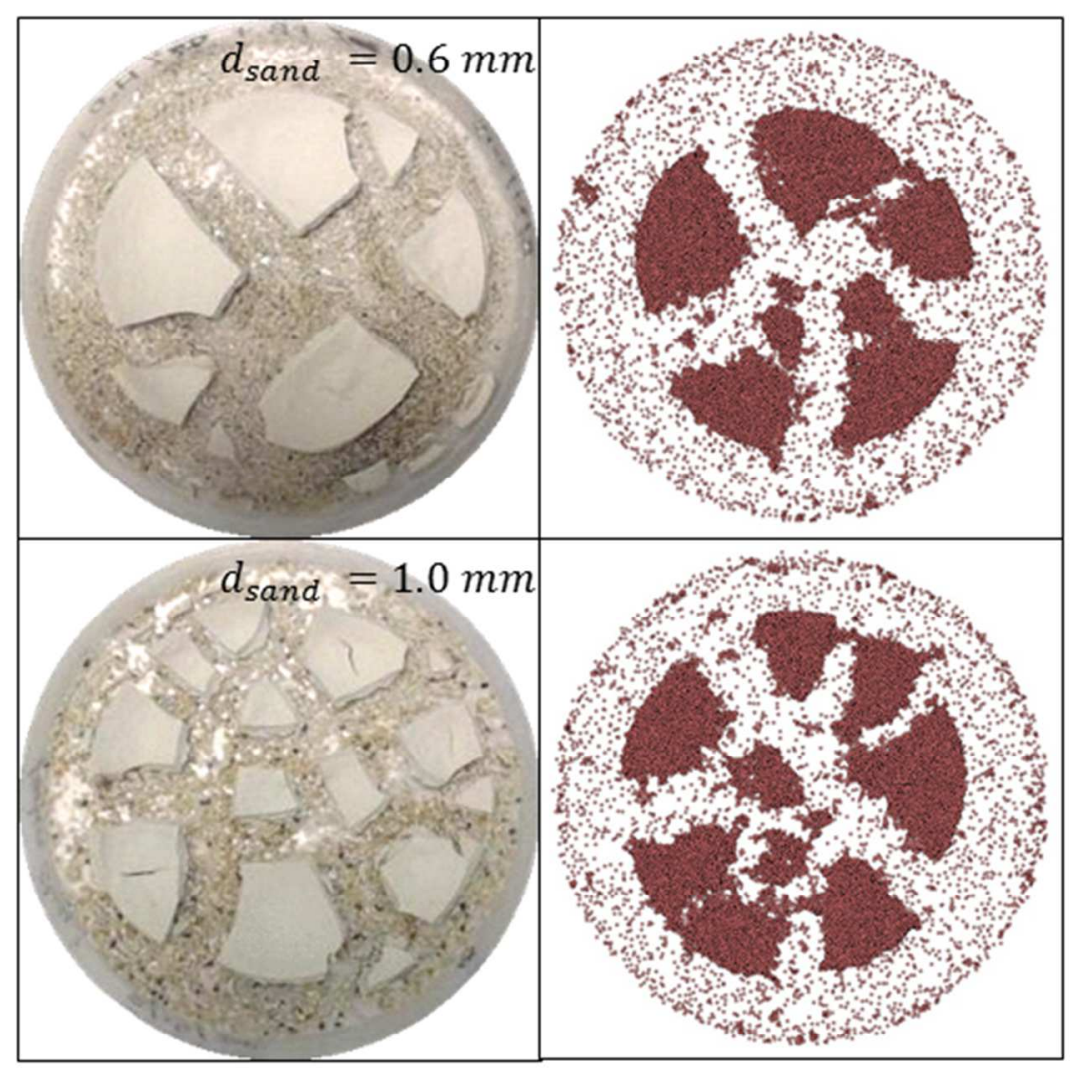

Figure 13. Comparison of final crack patterns of bentonites with different surface roughness 

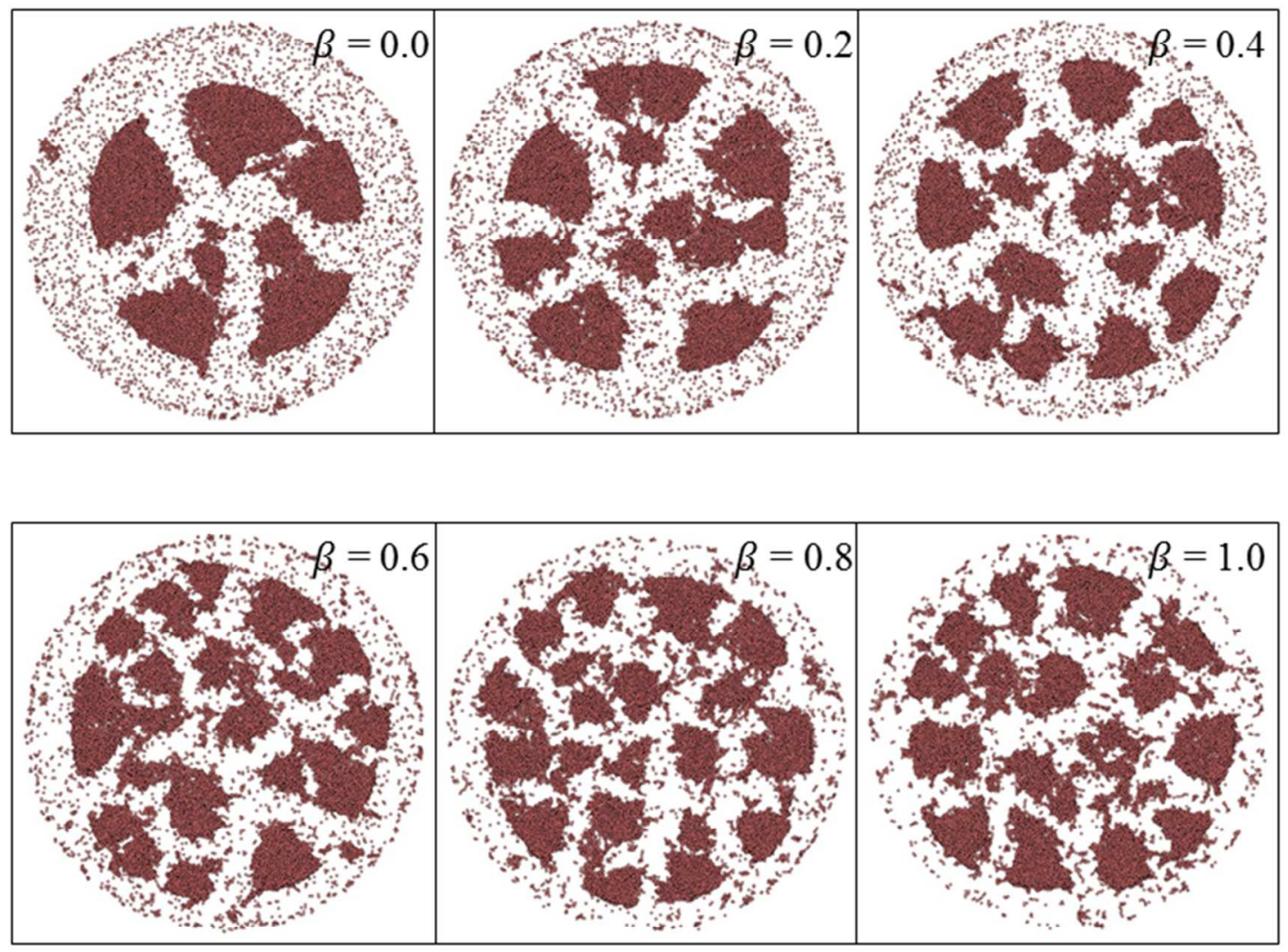

53 Figure 14. Final crack patterns of bentonites with different surface strength reduction factors 


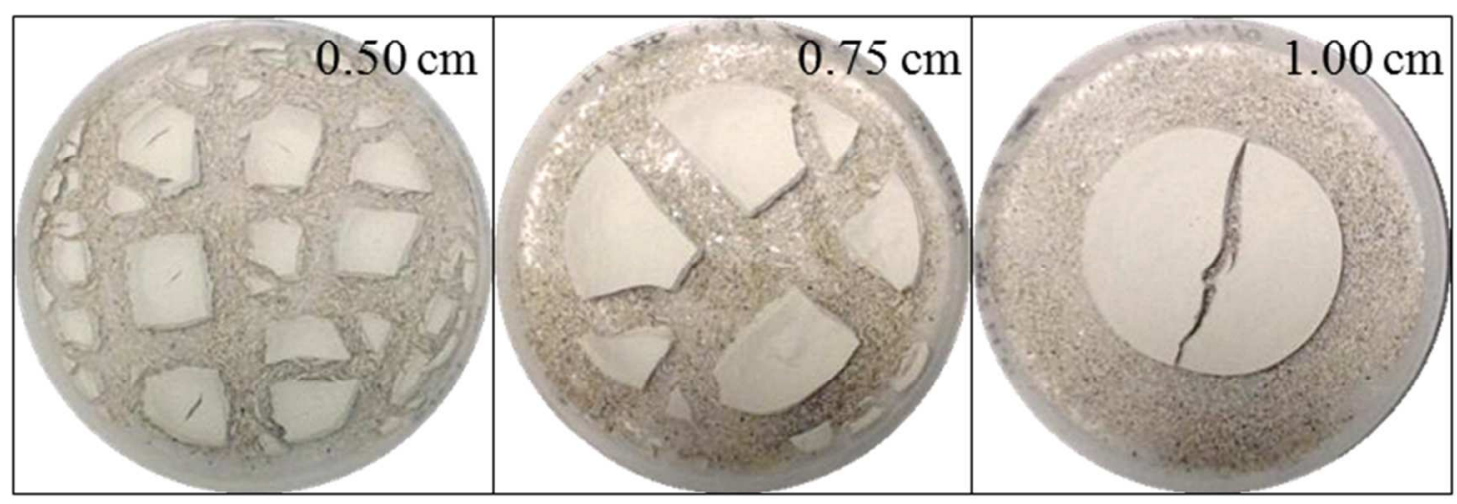

Coated with fine sand, $d_{\text {sand }}=0.6 \mathrm{~mm}$

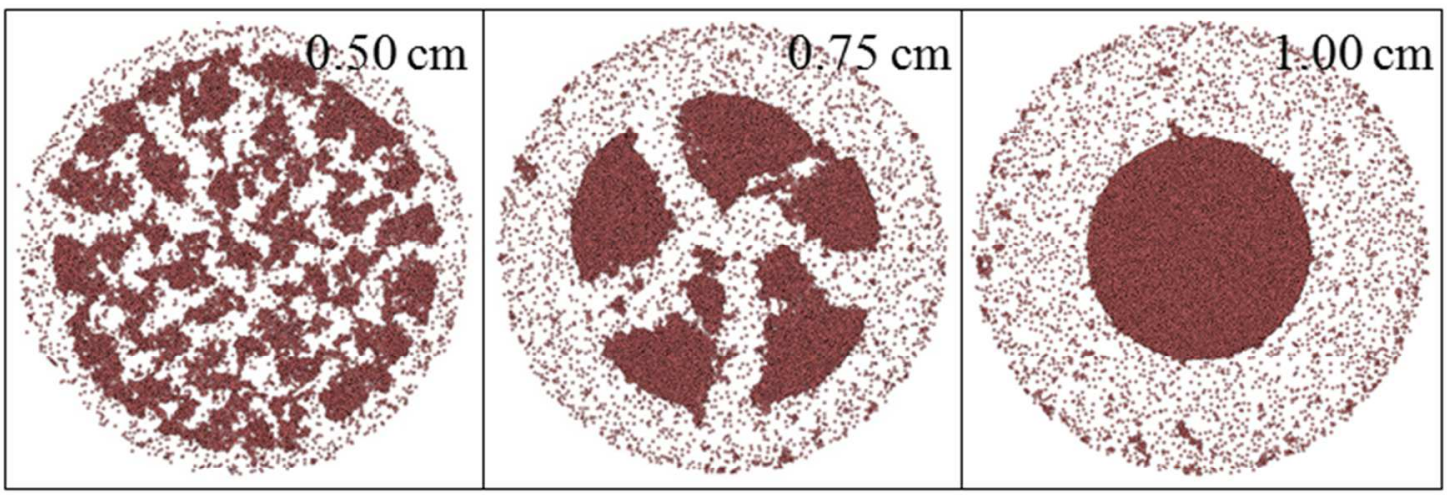

57

58 Figure 15. Comparison of final crack patterns of bentonites with different thicknesses $(\beta=0.0$,

$$
\left.d_{\text {sand }}=0.6 \mathrm{~mm}\right) \text {. }
$$

60 